\title{
Conceptualizing A Program Aimed at Empowering Beginning International Health Science Students for A Successful Transition to University
}

\author{
Joy Cayetano-Penman ${ }^{1}$, Gulzar Malik$^{1}$, Kerry Hampton ${ }^{1}$ and Yaping Zhong ${ }^{1 *}$ \\ ${ }^{1}$ Monash University, Australia \\ *Correspondence: nevazhongbao@163.com
}

\begin{abstract}
International health science students face many challenges at the beginning of their courses, including a lack of awareness of cultural differences, adjusting to academic expectations, communication difficulties, clinical placement challenges, financial pressures, maintaining cultural and religious practices, discrimination, and emotions such as loneliness and being homesick. This study aims to assist beginning international students enrolled in health sciences programs to adapt to university life and achieve academic success by expanding their coping abilities and selfmanagement strategies. A survey approach was used to evaluate the pilot program named EMPOWERMENT. All first-year international students who participated in the EMPOWERMENT program were invited to complete a post-training questionnaire after the program. The results revealed that increased resilience and improved skills to manage stress were the most frequently reported outcomes of the program. In acquiring these important skills, the students valued the opportunity to share their experiences and learn from each other.

Keywords: international students, university transition, health science courses, resilience, coping, self-management strategies
\end{abstract}

\section{Introduction and Background}

International students make a substantial contribution to Australia's economy and social culture. According to International Education Association of Australia statistics (2019), the Australian international education sector has contributed 37.6 billion to the Australian economy, up by $\$ 5$ billion from the previous financial year, representing a growth of $15 \%$ since the $2016-17$ financial

Received February 16, 2020; revised April 28, 2020; July 13, 2020; August 16, 2020; accepted September 19, 2020; electronically published March 2, 2021

Journal of Comparative \& International Higher Education

March, 2021, Vol. 13, No. 1, pp. 28-55.

DOI: 10.32674/jcihe.v13i1.1994

(C) 2021 Journal of Comparative \& International Higher Education. All rights reserved. 
years (Australian Bureau of Statistics, 2019). International education is Australia's fourth-largest export earner after coal, iron ore, and natural gas (Australian Bureau of Statistics, 2019). In addition, the Australian Department of Education, Skills, and Employment (2020) has reported that Australia is the third most popular education destination globally, with approximately 758,154 international students studied in Australia in 2019, up by $9.4 \%$ in growth.

Research exploring students' experiences of studying and living in Australia has shown that students face a few complex challenges in the initial stages as they adjust to living and studying in a foreign country (Australian Universities Guide, 2018). Several studies highlighting low well-being among international students have consistently raised concerns about student adjustment, academic progress, and overall quality of their university experience (Marginson, et al., 2010; Forbes-Mewett \& Sawyer, 2011). For instance, an Australian scoping review by McKenna et al. (2017) has identified several factors that influence the psychological well-being of international students in the health professions, including increased levels of anxiety and stress in trying to meet family expectations, resulting in lower quality of life and unsatisfying personal relationships. The review concluded with the recommendation that universities should develop tailored interventions to support international students throughout their degree program both for academic success and overall health and well-being.

Considering that universities are essential venues for promoting mental health and wellbeing, many educational institutions have developed services in common and/or specifically for domestic and international students (Ong \& Ramia, 2009). However, the problem for international students is that these services are often underutilized because of their help-seeking attitudes. Helpseeking refers to the behaviour of a student actively searching for and requesting academic or nonacademic help through a variety of services in the university (Gorczynski, et al., 2017). A 2010 study by Martin on service utilization found that students were reluctant to use the services available to them because they did not want to disclose their mental health conditions to the university (Martin, 
2010). They feared being stigmatized and discriminated in their studies and concerned about confidentiality issues.

Because of being unsupported, they became disadvantaged, resulting in their underperformance. Students preferred to seek help from family and friends rather than from university counselors or private counselors (Reavley, et al., 2012; Goodwin, et al., 2016). Thus, while it appears that students have specific reasons for not accessing university-provided counseling and other similar services, a clear need remains, as does the need for the articulation of an engagement and development strategy that is relevant and meaningful for this potentially vulnerable group of students.

Many universities have developed orientation programs that support the transition of firstyear students to higher education. Heaney and Fisher (2011) report that newly enrolled students lack confidence in their ability to succeed in academic settings and need additional help in gaining the knowledge, attitudes, and skills to help them adjust and make a smooth transition into the university community. Most Australian universities hold their orientation in the week immediately preceding each semester. During the program, students are introduced to several university services that support students in their educational and personal goals, along with several information sessions and fun social activities that are designed to set students up for success in their studies (International Education Association of Australia, 2020). It is acknowledged that orientation programs are essential in helping students persist (Manee, et al., 2015). However, in most instances, the orientation activities are organized for a short period of time, and therefore more is needed to be done for international students considering their increasing numbers in various programs.

Evidence suggests that health science degree students, in particular, experience significant transitional stress as compared to students enrolled in other disciplines (McKenna, et al., 2017; Penman \& Thalluri, 2014). While experienced by domestic and international students, the main stressors for students enrolled in health science courses were language issues, adaptation to a foreign education system, and settlement, finance, and health challenges (He, et al., 2012). In 
addition, adjusting to a new academic structure was raised in many studies, particularly a requirement to study online, be self-directed learners, classroom interaction and largely clinical placements in health services, reported as key stressors (Malau-Aduli, 2011; McDermott-Levy, 2011).

To support health science and international students, it is argued that transition programs will be more meaningful if they are extended well beyond the initial orientation events to support students through the first semester and beyond (Krause, 2006). Moreover, it has been found that institution-level transition programs are most successful if accompanied by discipline-based initiatives designed to support students within their disciplinary subgroups (Yu, et al., 2017). This approach has been proven to be more beneficial and meaningful to international students as the programs are considered to be both authentic and relevant to their proposed course of study and future careers (Arhin \& Wang'eri, 2018).

The literature on international student persistence reports that students in their first year of university are much more engaged and devoted. Balancing between academic, work, and social life, academic integration, and attaining the right skills to cope with stressors contribute to international students' academic success and mainly to their retention (Andrade, 2006-2007; Mamiseishvili, 2012). However, these results can only be achieved if students are provided with support from faculty members, peers, and other relevant staff, such as peer-pairing programs and interactions with faculty members outside of the classroom (Andrade \& Evans, 2009). Deil-Amen's (2011) study recommends the importance of connecting students with faculty, staff, and advisors who can mentor and support students early on to facilitate the process of students' integration on campus.

While much emphasis is generally placed on the transition to university, relatively little attention is given to the transition through the first year of university for health science international students. When the excitement of orientation subsides, what can be done to enhance the quality of the student experience? How can international students enrolled in health science degree courses be empowered to recognise stressors better and thus manage their challenges? Furthermore, how can such an approach be scaled up so that the discipline and potentially the university can better 
support international students? The above questions provided the catalyst for the rationale of the self-management program our group visualized and piloted.

\section{Aims}

This study aims to assist beginning international students enrolled in Nursing and Midwifery, Nutrition, Dietetics and Food, and Occupational Therapy Masters' programs at our university to transition and adapt to university life and achieve university success by expanding their coping abilities and self-management strategies. After providing the background for the development of a self-management program, this paper will address three objectives, namely, to describe the conceptualization of the program that was developed; report on the initial reactions of the participants on the inaugural program that was conducted, and draw on the lessons learned to inform future program offerings.

\section{The Conceptualization of the Program}

The study was conducted at a public research university based in Melbourne, Australia. The university website (2020) states that it is the second oldest university in Victoria, having several campuses, four of which are in Victoria and one in Malaysia, and has a research and teaching centre in Prato, Italy, a graduate research school in Mumbai, India and a graduate school in Suzhou, China. It is a member of Australia's prestigious Group of Eight, a coalition of Australia's eight leading research universities (Group of Eight Australia, n.d.), and is consistently ranked among the world's top 75 universities (Q.S. World University Ranking, 2020). Students at this university come from diverse backgrounds, including in health science disciplines, hence the significance of this research for the international students studying at the university.

In preparing the EMPOWERMENT program, a reference group was formed consisting of academics with extensive teaching experience from three disciplines of Nursing and Midwifery, Nutrition, Dietetics and Food, and Occupational Therapy. Other members included a lecturer from the Student Academic Support Unit and the Director of International Student Welfare. The group 
determined the content of the program, the pedagogical theory supporting the initiative, and the design, format, and delivery of the workshops. Bandura's $(1986,2019)$ social cognitive theory was used to underpin the conceptualization of the EMPOWERMENT program for international students. This theory was specifically chosen because it conceptualizes learning that occurs in a 'social context with a dynamic and reciprocal interaction of the person, environment, and behaviour' (LaMorte, 2019). As such, it sets out a structure of human thought and behaviour, where the factors behaviour, cognition, and environment interacted and influenced each other to give the desired outcome.

Figure 1 captures the principles that underpin the program, illustrating the interactions of the key factors that bring about behavioural change, for example, self-efficacy. The arrows in the figure are fluid, vibrant, continuous, and interacting lines connecting the major concepts. Both cognition and the environment influence behaviour and vice versa.

\section{Figure 1}

Social Cognitive Theory

\section{iniviviti}

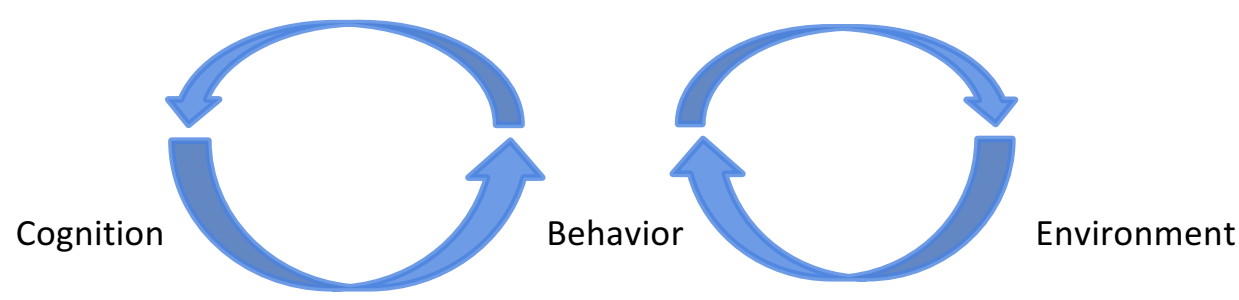

Self-efficacy

Using the social cognitive theory, the behaviour (being self-efficacious), will be strengthened following participation in the proposed program. Self-efficacy is defined as the ability to achieve what one set out to achieve, such as pass an exam, complete a course, deliver a presentation, or survive and thrive at university (Mitchie, et al., 2014). To increase the levels of self-efficacy, 
knowledge, skills and resources about empowerment strategies, and an environment that is supportive to raise the individual's confidence is necessary. In line with the theory, the idea is to shape the environment to provide opportunities for behavioural change, assisting with the changes, and offering resources and support, which may encourage durable behaviour change. It is also vital to recognize environmental constraints that might deter behaviour change. Thus, during the sessions, challenges, and barriers to performing the expected change in behaviour are explored, acknowledged and strategies are presented to overcome these barriers. Figure 2 summarizes the program. The action phases are occurring sequentially, as demonstrated.

\section{Figure 2A\&B}

The Conceptualization of the Empowerment Program

2A. Empowerment strategies (Cognition)

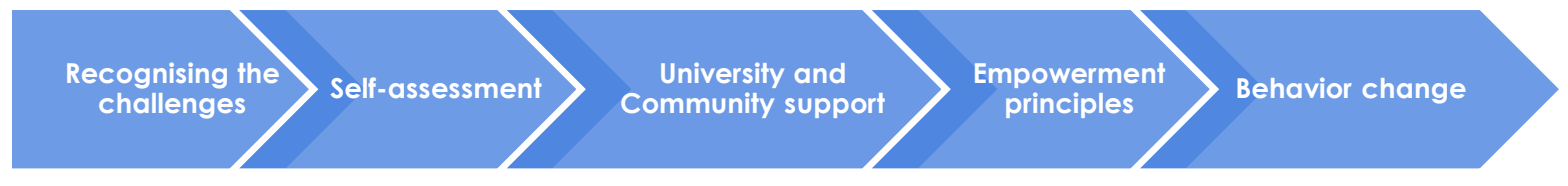

2B. Supportive mechanisms (Environment)

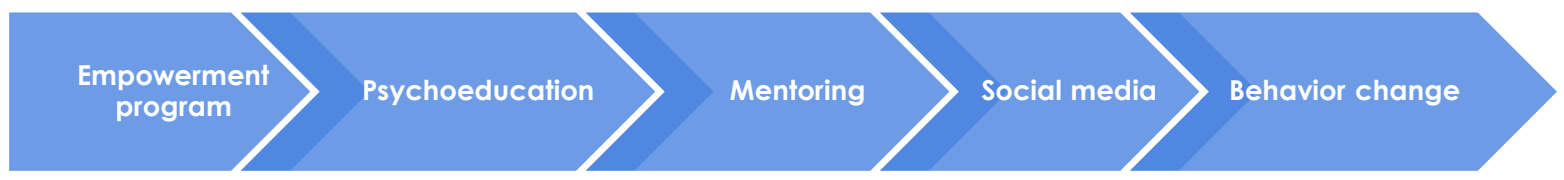

Cognition $(2 \mathrm{~A})$ is a mental process that is informed by awareness, perception, understanding, thinking, and reasoning, as well as by past recollections and experiences (Braungart, et al., 2019). It is enhanced by the identification of the issues or problem (recognizing the challenges), appraising self, support available, the conceptualization of the engagement strategy, planning of the strategy, executing the plan, monitoring, and critically appraising for validity and usefulness, the reflection of areas for improvement, and working towards sustainability (Pathak, 2020).

The supportive mechanisms (2B) refer to the empowerment workshops, which included psychoeducation, peer mentoring and the Facebook page that will be maintained for and by the 
participants. The action phases are used to demonstrate these events in order to cause cognitive and behavioral change. The principles of empowerment and psychoeducation used in the pilot were first conceptualized from a systematic review of health and wellness literature conducted initially by some of the authors. These were also informed by personal experiences of the participating lecturers with many years of teaching experience, and the lessons learnt from past programs conducted by some lecturers to assist the smooth transition of students to the university. The resultant strategies were summarized in the acronym EMPOWERMENT: E-Engagements with others/relationships; M-Mindfulness; P-Positive thinking; O-(going) Outdoors; W-(emphasis on) Wellness; E-Entertainment/leisure/hobby; R-Resilience/rest/relaxation; MMeditation/spirituality/belief in Higher Being; E- exercise/physical activity; N-Nutrition, Healthy eating; T-Temperance in activities such as phone/computer use, alcohol (Baik, et al., 2016; Eat for Health: Australian Dietary Guidelines, 2013; Newstart: Health is wealth, 2019; Penman, 2015; Penman, et al., 2017; Staying well, 2018; Van Der Riet, et al., 2015). The outcome at the conclusion of the program was that the students would come up with their strategies for surviving and thriving in the university.

The theory also proposes that human functioning could be understood from basic capabilities,

i.e., symbolic thought, forethought, observational learning, self-regulation, and self-reflection (Mitchie, et al., 2014). In providing certain tasks, strategies and activities that enhance those capabilities, specific deliverables may be achieved facilitating behavioural change (see Appendix 1).

\section{Our EMPOWERMENT programs}

The EMPOWERMENT program we conceptualized consisted of three components: workshops, a peer-mentoring program, and online support with resources through a closed Facebook page. There were four (4) two-hour workshops, spread across the second semester.

In the first session, students' expectations of university life were explored, along with their attributes and perceived strengths they brought with them to the university. The identification of resources students could utilize to enhance their academic success as well the demands and possible 
stresses they might encounter or are already encountering in their courses followed. Some tips on cultural adjustment and sampling of iconic Australian foods concluded the session.

The second session focused on maintaining good health and well-being, and self-assessment of current self-management strategies. The ways to build from one's strengths and resources were emphasized. The session introducing the students to aerobic exercise was well-received.

Additionally, students were provided with strategies to adjust to an active learning environment, heavy academic workloads, and skills to manage time effectively.

Session three was dedicated to the support the university and general community provided to ensure students' success in their studies and to maintain and promote their health and wellbeing. Mindfulness and meditation were some strategies shared with students. Also, students developed action plans on balancing study, life, health, and well-being.

The final topic offered insights into resilience, and how one might foster this underpinned by various theories of coping and change. The last session also emphasised creating a successful life in university and beyond by underlining the tips to manage risks and being prepared for them. Importantly, in this session, students were given time and support to come up with their version of 'EMPOWERMENT'. The students were able to contribute their understanding of coping and thriving at university. Finally, an evaluation of the learning that happened during the program was conducted individually and as a group.

Along with the workshops, online resources and interactive platform through a closed Facebook page were provided to students to ensure continued access to support from co-mentees, mentors, and staff. Moreover, the first-year international students were introduced to senior students/mentors. The roles of mentors were to share their experiences about the university, help mentees achieve their goals during the transition; and assist the mentees personal and professional growth. The idea was to gradually establish mental health/well-being champions who are equipped with resources to help mentees' wellbeing and resilience development as well as promote support 
services. Mentors were supported and trained by the researcher team. The mentees were encouraged to act as mentors for the newly commencing students in the following year.

\section{Methodology}

A survey was used to evaluate the inaugural program. All participants were invited to complete a post-training questionnaire after the program. The one-minute Harvard questionnaire (Drummond, 2007; Stead, 2005) was used to collect information from the students. This survey had high completion rates, that could be adapted to most contexts, deemed simple to prepare and administer, easy to execute, and generally well received, making it ideal for young participants who might find long questionnaires tedious to complete. The questionnaire had five open-ended statements that asked: In your view, what was/were the most important outcome/s gained from attending the program? List the best aspects of the program and why? What aspect of the program could be included or expanded for future offerings? How might this program impact on you? Other comments relating to your satisfaction/dissatisfaction of the program were also gathered. For this pilot study, a validity test to check the characteristic the test measures and how well the test measures that characteristic was not performed, however, future program evaluations will consider this test.

\section{Data Collection}

Information letters explaining the EMPOWERMENT program, its objectives, benefits, explanations of student involvement, and potential outcomes, were distributed to the students through subject and course coordinators. These students were the first-year international students from the Nursing and Midwifery, Nutrition, Dietetics and Food, and Occupational Therapy masters' program during the second semester of 2018, as well as senior international students from the disciplines who functioned as mentors. Permission from the Heads of Schools was obtained to access emails of the potential students through university admission systems. In total, nine students participated in the program. Ethical approval was obtained from the university ethics committee. 


\section{Data Analysis}

Content analysis was conducted according to the steps set out by Chambers and Chiang (2012). This type of analysis involves labelling, organizing, and interpreting data into a set of codes, concepts, themes, or categories (Krippendorff, 2004; Neville \& Whitehead, 2020). Questionnaires were collected and organized into a text. During labelling, two researchers worked on the text independently and highlighted relevant passages within each of the comments. Next, labels were organized and grouped, as a process of categorizing. Researchers inductively generated the initial codes after reading the comments carefully. To place the content appropriately, the text was categorized into themes such as, the most important outcomes/gained from attending the program, the best aspects of the program, aspects of the program that could be included or expanded and impact of the program on participants.

The trustworthiness of findings was achieved in two ways (Bettini, et al., 2017, Schreier, 2012). Firstly, by peer debriefing during each stage of data analysing, as two researchers coded the same text, met to discuss their ideas about codes, and worked to reach a consensus. The researchers also continued the discussions about the recognition of the findings until developing a team consensus. Secondly, the researchers-based conclusions on data and used data to identify how various ideas worked together to support the findings. Tables were created, which revealed the frequency of each category.

\section{Results}

All nine students who participated in the program completed the questionnaire. The demographic characteristics of the sample included six Master of Nursing Program students enrolled in the first semester, two Masters of Occupational Therapy students and one student from the Dietetics program. There were six mentees and three mentors. The findings are presented in themes comprised of the most important outcomes/gained from attending the program (Table 2); the best aspect of the program (Table 3); aspects of the program that could be included or expanded (Table 4); and additional comments if any. The impacts of the program on participants are also 
summarized. This pilot study revealed that there were many important outcomes from participating in the program. Becoming familiar with resilience and how to foster resilience was a common outcome. Participating students signified their interest expressing high satisfaction with the university's program.

\section{The Most Important Outcomes of the Program}

Analysis of Table 2 shows that three participants believed they had learnt resilience skills, which could help them improve their academic performance. By attending the program, they also believed that their coping skills had been increased. They incorporated the elements of EMPOWERMENT, such as regular exercises, mindfulness, healthy diet, and others in their daily lives, which participants anticipated to have an impact on their stress management skills relating to study and life pressures. For some participants, the program was about gaining support, positive encouragement and making new friends. They identified the various services available to them to enhance their academic skills which at times were recognized as a major source of stress. Overall, participants revealed that the program provided them with a platform to share their thoughts, challenges and at the same time exposed them to various coping skills which they could not only use to succeed in academic lives but could apply beyond the university. Additionally, the mentors cited that they learnt mentorship skills, including skills of sharing, being supportive and reflective.

Table 2

The Most Important Outcome/s Gained from Attending the Progam

\begin{tabular}{l|c}
\hline Categories & Frequency* \\
\hline 1. Resilience skills/ coping skills & 3 \\
2. Stress management/ Self-management & 3 \\
3. Empowerment/mentorship/study tips & 2 \\
4. Gaining encouragement and support & 2 \\
\hline
\end{tabular}


\begin{tabular}{l|l} 
5. Where to get help & 1
\end{tabular}

6. New friends

1

7. Time management

1

8. Interaction/sharing

* Number of times the response was made

\section{The Best Aspects of the Program}

Most of the participants reported that the program provided them with an opportunity to share their experiences with other students, which made them feel that they were not alone in their university journey (See Table 3). They exchanged ideas and gained inspiration from each other. Also, a wide range of activities to foster empowerment was integrated into the program, which was appreciated by the participants. They pointed out tips to manage time effectively, various coping skills, ways to manage stressors in academic life, which they found to be practical and useful.

Table 3

The Best Aspects of the Program

\begin{tabular}{l|c}
\hline Categories & Frequency* \\
\hline 1. Share experience and learn from others & 5 \\
2. Useful advice and information (academic, exam) & 3 \\
3. A wide range of activities to foster empowerment and relationships; & 3 \\
Time management; Exercise and resilience session: Multiple activities to & \\
engage & 2 \\
4. Coping skills in daily life; Manage myself & \\
5. Always being positive and supportive to every participant. always & 2 \\
cheer me up & \\
\hline
\end{tabular}

*Number of times the response was made 


\section{Aspects of the Program That Could Be Included or Expanded}

In the evaluation of the inaugural program, participants were asked to comment if there was any aspect that could be expanded or included (See Table 4). Participants preferred to include discussion on jobs prospects when they were students as well as after graduation. Some participants stated they wanted to have more interaction with mentors and students in the senior levels to learn from their experiences and reflections. Also, participants also highlighted the resilience and coping skills could be further expanded by organizing the program earlier in the semester and continued until the end of the semester.

Table 4

Aspect of the Program That Could Be Included or Expanded

\begin{tabular}{l|c}
\hline Categories & Frequency* \\
\hline 1. Information related to future job & 2 \\
2. More interaction with mentor/mentee & 2 \\
3. More interactive activities & 1 \\
4. More daily skills like cooking & 1 \\
5. Exercise & 1 \\
6. Resilience and time management & 1 \\
7. Start time- earlier, till the end of the semester & \\
\hline
\end{tabular}

* Number of times the response was made

\section{Impact of the Program on Participants}

The impact of the program on participants' personal and academic lives could be discerned from their comments. Attendees gained the desire to improve themselves and share their knowledge and understanding with others (altruism), motivate and inspire others which would possibly help them to be more self-aware, confident, and satisfied. Two mentors shared their views as follows: 
[I wish to] continue to improve myself and share more with others, become a role model.

Continue to be helpful and supportive; try to motivate and inspire others instead of making suggestions only. (Mentor 1)

I learned a lot from hearing others' experiences. I will try to achieve my goals effectively, keep motivating myself, helping others, and take care of myself. (Mentor 2) Behavioural changes were evident. Participants developed behaviours for self-caring by engaging in regular exercises and healthy lifestyle practices. Following are the remarks of two participants:

This program encourages me to be a member of the gym because I think I need to exercise and relieve pressure. Thanks a lot! (Mentee 1)

I start my exercise as a routine now. [I endeavour to] be more organized and positive for my future. (Mentor 3)

Moreover, they perceived the program had implications on their coping and resilience skills. By participating in the program, they were made aware of a variety of strategies that could be used in both personal and academic life challenges. See excerpts below:

Thinking about the challenge and difficulties which I might face, or I am facing. Having more ideas about how to cope with [the challenges and difficulties]. (Mentee 2) I understand that it is more than academic performance; there are a lot of important things and happiness in my life. (Mentee 3)

Several participants highlighted the learning gained from listening to the experiences and narratives of others and being reflective, which were highly applicable in times of difficulties. These sentiments were expressed as follows:

It's always good to listen to other personal stories. I can always learn from others and reflect on myself. (Mentor 2)

Think widely! When I face difficulty in academic life, I will be reflective [and work on solutions]. (Mentee 5) 
In the final section of the questionnaire, the participants were encouraged to provide further comments about the program. Five participants appreciated the program by expressing their enjoyment and approval; one felt well supported by others; one wanted a longer program, while another participant wished she could have contributed more to the program.

\section{Discussion}

The EMPOWERMENT program offered an integrated approach; involving student support units along with senior students who can offer mentorship, support, and help create "healthpromoting environments" in the first transition year and potentially beyond. There were several positive outcomes derived from conducting this program; most important was the impact on the students participating in the EMPOWERMENT program. For students, it helped to enhance their coping skills and resilience, thus assisting their smooth transition to university life. There were concrete plans, and changes discerned from their reflections, namely, being more reflective, caring for oneself, and committing to exercise and the gym.

For the mentors, the opportunity for personal and professional growth was equally evident. They desired to be role models for others by sharing their experiences of hardships and strategies used to overcome those. The mentors also gained positive aspiration as taking care of self, improving self, and reflecting on their practices for achieving academic success.

The proposed program could also impact on the university, as it has the potential to enrich university staff's impact and morale, resulting in better performance evaluations, improve student recruitment and retention, and more importantly better develop the coping and resilience skills and abilities of the students. Another critical success of the university was offering students interprofessional learning experiences when different disciplines come together with a similar purpose of adapting to university (Phillips, 2019). This EMPOWERMENT program is consistent with the expectations of the university that its staff collaborate with the community and work together to find creative, sustainable solutions to community members' concerns. 
The real and potential benefits of the program for the wider community are the preparation of future health professionals who can care for their health and well-being, as well as be equipped to care for others. This program is both transferrable to other disciplines and scalable across disciplines; and as such is efficient, effective, and sustainable.

There were several lessons from the pilot program, which will be beneficial for future program planning and implementation. In total, four sessions were offered throughout the semester; however, participants wished it would have extended for another semester. A recommendation will be forwarded to the relevant disciplines in the final report of the program as it would require consistent funding and resources. In response to the sub-optimal intake of participants in the inaugural program, the support from the university is deemed essential in marketing the program to students. Students tend to pay more attention when such initiatives are encouraged at the university level (Kuh, Kinzie, Schuh \& Whitt, 2011). Involving other disciplines and extending it across university programs may address the recruitment issue as well. With future iterations of program, it is worth inviting both international and domestic students and compare the findings of both the groups to evaluate the impact of the program. There could be similarities and differences in the challenges faced by both international and domestic students; however, future research is necessary to determine these.

Moreover, it is crucial to identify other competing programs which may have a similar purpose of assisting students to transition through the university particularly during the first academic year. Combining such programs will assist by easier scheduling of the sessions, given the difficulty in finding spots to schedule such program which is considered outside students' academic classes, and facilitating the use of collective resources for the successful implementation of the program. For future offerings, we also suggest more involvement of mentors to facilitate some sessions which may increase their capability, confidence, and ownership of the program. For a pilot 
study, a single university involving three disciplines is a sufficient sample size, with the view of using multiple universities in future offerings and evaluations.

\section{Conclusion}

The challenges confronting international students are well known. It is therefore essential to build and evaluate student independence and support networks as part of a better integrated academic and social transition program. Various universities have developed their support strategies for creating "health-promoting environments". The EMPOWERMENT program, with the aims of assisting international students enrolled in various health science programs to transition and adapt to university life and achieve university success by expanding their coping abilities and selfmanagement strategies, was conceptualized and piloted in this study.

The social cognitive theory was used to direct our program, where cognition, behaviour, and environmental factors interacted. The theory underpinning the program informs the program elements, which in turn influence the outcomes and evaluation as well as the future strategies and programs.

A questionnaire with five open-ended statements querying students' perceptions about the program was used to evaluate the pilot program. Participant responses revealed that resilience and stress management skills and psychoeducation were the most important outcomes. The best aspect of the program was the opportunity to share and learn self-management skills from each other.

Future directions for research include canvassing a bigger sample of participating international students, testing hypotheses, and continuously supporting international students to achieve academic success and transition and adapt to university. The results of this study should be tested in a full study with a large sample size of international and domestic students and with validated instruments in the future. With a larger dataset, the conclusions about the program will be generalizable.

\section{Acknowledgements}


The authors would like to acknowledge the Faculty of Medicine, Nursing and Health Sciences [a university masked for blind review] for their funding support. We also appreciate the team of researchers who had conceptualized and implemented the project ideas.

\section{Declaration of interest}

The authors declare no conflict of interest.

\section{Ethical Statement}

This study has been approved by [a university masked for blind review]. 6920-11-40

\section{Author Note}

Joy Cayetano-Penman, PhD RN, Senior Lecturer, Nursing \& Midwifery, Monash University Australia. Email: joy.penman@monash.edu

Gulzar Malik, PhD RN, Senior Lecturer, Nursing \& Midwifery, La Trobe University Australia; Affiliate, Nursing \& Midwifery, Monash University. Email: g.malik@latrobe.edu.au

Kerry Hampton, PhD RN, Lecturer, Nursing \& Midwifery, Monash University, Australia. Email: kerry.hampton@monash.edu

*Yaping Zhong, PhD \& Research Assistant, Nursing \& Midwifery, Monash University Australia. Email: nevazhongbao@163.com 
Andrade, M. S. (2006-2007). International student persistence: integration or cultural integrity. Journal of College Student Retention, 8(1), 57-81.

Andrade, M. S., \& Evans, N. W. (2009). Keys to persistence - International students in higher education. In M. S. Andrade \& N. W. Evans (Eds.), International students: Strengthening a critical resource (pp. 43-72). Rowman \& Littlefield.

Arhin, V., \& Wang'eri, T. (2018). Orientation programs and student retention in distance learning: the case of University of Cape Coast. Journal of Educators Online, 15(1).

Australian Bureau of Statistics. (2019). Economic value to Australia. https://www.abs.gov.au/ Australian Department of Education, Skills and Employment. (2020). International student data monthly summary. https://internationaleducation.gov.au/research/InternationalStudentdata/Documents/MONTHLY\%20SUMMARIES/2019/Dec\%202019\%20MonthlyInfogra phic.pdf

Australian Universities Guide. (2018). International student numbers at Australian universities. http://www.australianuniversities.com.au/directory/international-student-numbers/

Baik, C., Larcombe, W., Brooker, A., Wyn, J., Allen, L., Brett, M., Field, R., \& James, R. (2016). A framework for promoting student mental wellbeing in universities. Enhancing student wellbeing. https://melbourne-

cshe.unimelb.edu.au/_data/assets/pdf_file/0016/2302603/MCSHE-Student-WellbeingFramework_FINAL.pdf

Bandura, A. (1986). Social foundations of thought and action: A social cognitive theory. Prentice-hall series in social learning theory. Prentice-Hall.

Bandura, A. (2019). Applying theory for human betterment. Perspectives on Psychological Science, 14(1), 12-15. https://doi.org/10.1177/1745691618815165

Bettini, E., Amber, B., Thomas, R., Kimerling, J., Choi, N., \& Mcleskey, J. (2017). Cultivating a community of effective special education teachers: local special education administrators' roles. Remedial and Special Education, 38(2), 111-26. 
Braungart, M. M., Braungart, R. G., \& Gramet, M. M. (2019). Applying learning theories to healthcare practice. In S. B. Batable (Ed.), Nurse as educator (5th ed.) (pp. 69-116). Jones \& Bartlett Learning.

Chambers, T., \& Chiang, C. (2012). Understanding undergraduate students' experience: a content analysis using NSSE open-ended comments as an example. (Report). Quality and Quantity, $46(4), 1113-1123$.

Deil-Amen, R. (2011). Socio-academic integrative moments: rethinking academic and social integration among two-year college students in career-related programs. Journal of Higher Education, 82(1), 54-91.

Drummond, G. (2007). Programme feedback: it only takes a minute. International Journal of Educational Management, 21(1), 29-36.

Eat for Health: Australian Dietary Guidelines (2013). Retrieved from:

https://www.eatforhealth.gov.au/sites/default/files/content/n55_australian_dietary_guideli nes.pdf

Forbes-Mewett, H., \& Sawyer, A-M. (2011). Mental health issues amongst international students in Australia: Perspectives from professionals at the coal-face. In S. Threadgold, \& E. Kirby (Eds.), The annual conference of the Australian Sociological Association 2011: Local lives/Global networks. Conference Proceedings. Refereed Papers (pp. 1 - 19). The Australian Sociological Association (TASA).

Goodwin, J., Laura B., Kelly, P., Mccarthy, K., \& Horgan, A. (2016). Help-seeking behaviors and mental well-being of first year undergraduate university students. Psychiatry Research, 246, 129-35.

Gorczynski, P., Sims-Schouten, W., Hill, D., \& Wilson, J. C. (2017). Examining mental health literacy, help seeking behaviours, and mental health outcomes in UK university students. Journal of Mental Health Training, Education and Practice, 12(2), 111-120. 
Group of Eight Australia. (n.d.). Group of eight universities.

https://go8.edu.au/files/docs/page/group_of_eight_universities_brochure_-_english_final_low-res.pdf

He, F. X., Lopez, V., \& Leigh, M. C. (2012). Perceived acculturative stress and sense of coherence in Chinese nursing students in Australia. Nurse Education Today, 32(4), 345-50. https://doi.org/10.1016/j.nedt.2011.05.004

Heaney, A., \& Fisher, R. (2011). Supporting conditionally-admitted students: a case study of assessing persistence in a learning community. Journal of the Scholarship of Teaching and Learning, 11(1), 62-78. http://search.proquest.com/docview/2387862045/.

International Education Association of Australia. (2020). International education by numbers. https://www.ieaa.org.au/documents/item/1151

Krause, K. L. (2006). Transition to and through the first year: Strategies to enhance the student experience. In Inaugural Vice-Chancellor's Learning and Teaching Colloquium. University of the Sunshine Coast.

Kuh, G. D., Kinzie, J., Schuh, J. H., \& Whitt, E. J. (2011). Student success in college: Creating conditions that matter. Jossey-Bass A Wiley Imprint.

Malau-Aduli, B. S. (2011). Exploring the experiences and coping strategies of international medical students. BMC Medical Education, 11(1), 40. https://doi.org/10.1186/1472-6920-11-40

Mamiseishvili, K. (2012). International student persistence in U.S. postsecondary institutions. Higher Education, 64(1), 1-17. https://doi.org/10.1007/s10734-011-9477-0

Manee, F. M., Khoiee, S. A., \& Eghbal, M. K. (2015). Comparison of the efficiency of self-awareness, stress management, effective communication life skill trainings on the social and academic adjustment of first-year students. Psychology and Behavioral Sciences, 3, 18-24.

Marginson, S., Nyland, C., Sawir, E., \& Forbes-Mewett, H. (2010). International student security. New York, United States of America: Cambridge University Press. 
Martin, J.M. (2010). Stigma and student mental health in higher education. Higher Education Research and Development, 29(3), 259-74.

McDermott-Levy, R. (2011). Going alone: the lived experience of female Arab-Muslim nursing students living and studying in the United States. Nursing Outlook, 59(5), 266-277.e2. https://doi.org/10.1016/j.outlook.2011.02.006

Mckenna, L., Robinson, E., Penman, J., \& Hills, D. (2017). Factors impacting on psychological wellbeing of international students in the health professions: a scoping review. International Journal of Nursing Studies, 74, 85-94.

Mitchie, S., West, R., Campbell, R., Brown, J., \& Gainforth, H. (2014). ABC of behaviour change theories. Silverback Publishing.

Neville, S., \& Whitehead, D. (2020). Analysing data in qualitative research. In D. Whitehead, C. Ferguson, G. LoBiondo-Wood, \& J. Haber (Eds.), Nursing and midwifery research methods and appraisal for evidence-based practice (6th ed.) (pp. 136-155). Elsevier Australia.

NEW START. (2019). NEW START Health Program / 8 Laws of Health / Eight Natural Doctors. https://leavesoflife.org/new-start-eight-natural-remedies/

Ong, D., \& Ramia, G., (2009). Study-work-life balance and the welfare of international students. Labour \& Industry: A Journal of the Social and Economic Relations of Work, 20(2), 181-206.

Pathak, R. (2020). 5 phases of project management (PMP). Retrieved from https://projectmanagement.com/project-management-phases

Penman, J., Sathasilvam, S., Goel, K., McCracken, T., \& Webby, B. (2017). Caring for your own and for other's mental health: A partnership approach. Paper presented at the International Conference of the Australian Association for Research in Education, Canberra, Australia.

Penman, J. (2015). Empowering female immigrant nurses to care for their own mental health. Paper presented at the 26th International Nursing Research Congress, Sigma Theta Tau International Honor Society of Nursing. 
Penman, J., \& Thalluri, J. (2014). Addressing diversity in health science students by enhancing flexibility through e-learning. The Electronic Journal of e-Learning, 12(1), 89-100. www.ejel.org; ISSN 1479-4403.

Phillips, J. (2019). An interprofessional learning experience for health professions students. AORN Journal, 107(3), 373-76.

QS World University Ranking (2020). https://www.topuniversities.com/university-rankings/worlduniversity-rankings/2020

Reavley, N. J., Terence V. M., \& Anthony F. J. (2012). Actions taken to deal with mental health problems in Australian higher education students. Early Intervention in Psychiatry, 6(2), 159-65.

Schreier, M. (2012). Qualitative content analysis in practice. SAGE.

Staying well. (2018). Managing symptoms of anxiety, depression and suicide. Beyond Blue. https://www.beyondblue.org.au/get-support/staying-well

Stead, D. R. (2005). A review of the one-minute paper. Active Learning in Higher Education, 6(2), 118-31.

LaMorte, W. W. (2019). The social cognitive theory. https://sphweb.bumc.bu.edu/otlt/MPHModules/SB/BehavioralChangeTheories/BehavioralChangeTheories5.html\#: :text=Social\%20C ognitive\%20Theory,The\%20Social\%20Cognitive\%20Theory,person\%2C\%20environment\%2C\%20and\%20behavior Van Der Riet, P., Rossiter, R., Kirby, D., Dluzewska, T., \& Harmon, C. (2015). Piloting a stress management and mindfulness program for undergraduate nursing students: Student feedback and lessons learned. Nurse Education Today, 35(1), 44-49.

Yu, M., Brown, T., \& Farnworth, L. (2017). Embracing international students in Occupational Therapy higher education in Australia: challenge or asset? Australian Occupational Therapy Journal, 64(6), 501-04. https://doi.org/10.1111/1440-1630.12389 


\section{Appendix 1}

Basic capabilities to develop to achieve behavioural change

\begin{tabular}{|c|c|c|}
\hline Capabilities & $\begin{array}{c}\text { Essential Tasks, Strategies and } \\
\text { Activities }\end{array}$ & Program Deliverables \\
\hline 1 & $\begin{array}{l}\text { Identifying interacting behaviour, } \\
\text { cognitive and environment } \\
\text { factors } \\
\text { Plan an engagement strategy by } \\
\text { outlining the anticipated } \\
\text { outcomes } \\
\text { Identify long-term outcomes, } \\
\text { medium-term and short-term } \\
\text { outcomes } \\
\text { Clarify motivators and guidelines } \\
\text { for action }\end{array}$ & $\begin{array}{l}\text { Develop engagement strategy } \\
\text { Set short-term outcome } \\
\text { (knowledge about university } \\
\text { support available), medium- } \\
\text { term (improved knowledge and } \\
\text { skills to cope in university), } \\
\text { long-term (expanded coping } \\
\text { strategies, increased } \\
\text { knowledge and skills of coping) } \\
\text { Set goals and aims }\end{array}$ \\
\hline Forethought & Assess readiness and needs & Self-reflection of previous \\
\hline
\end{tabular}




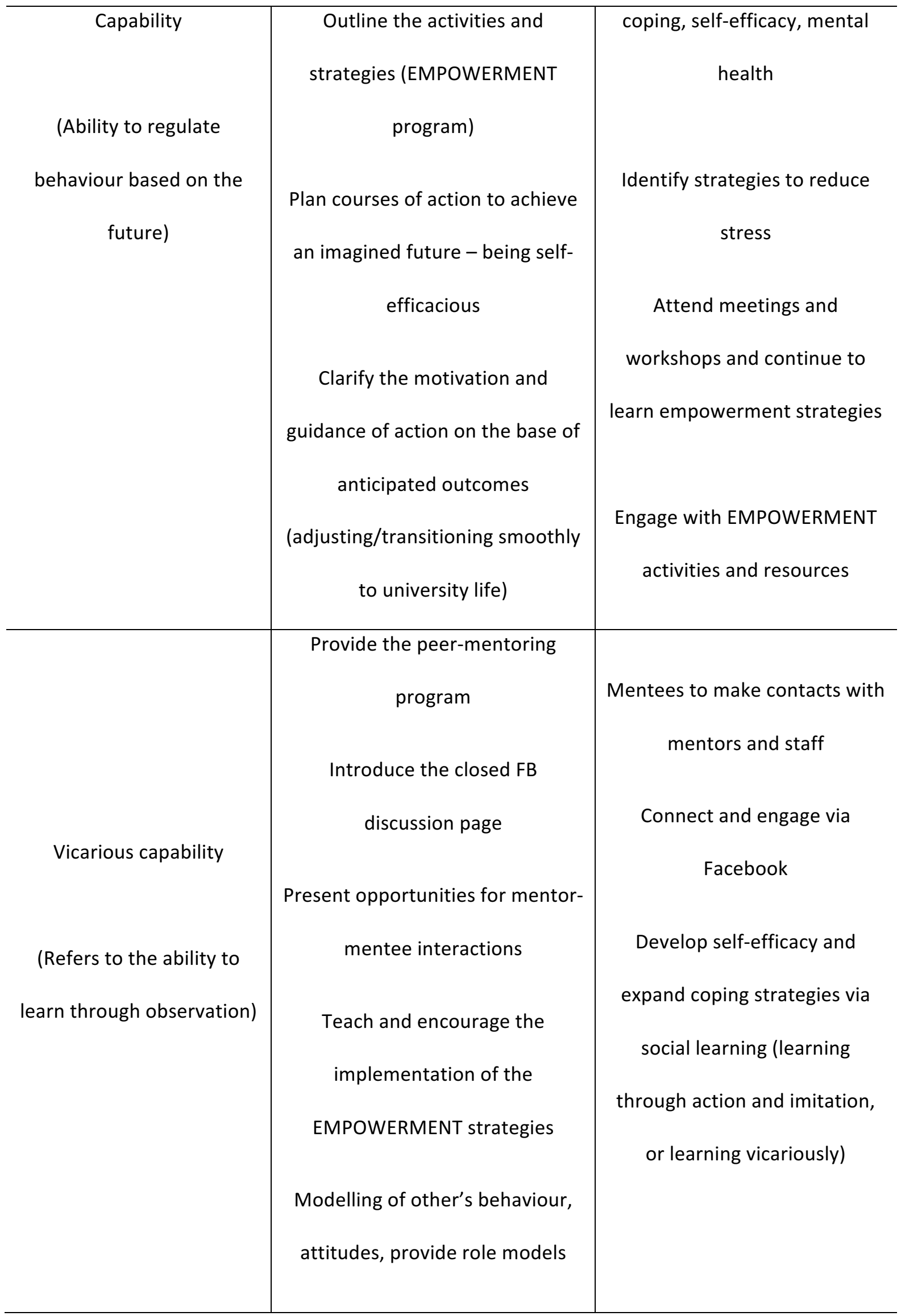




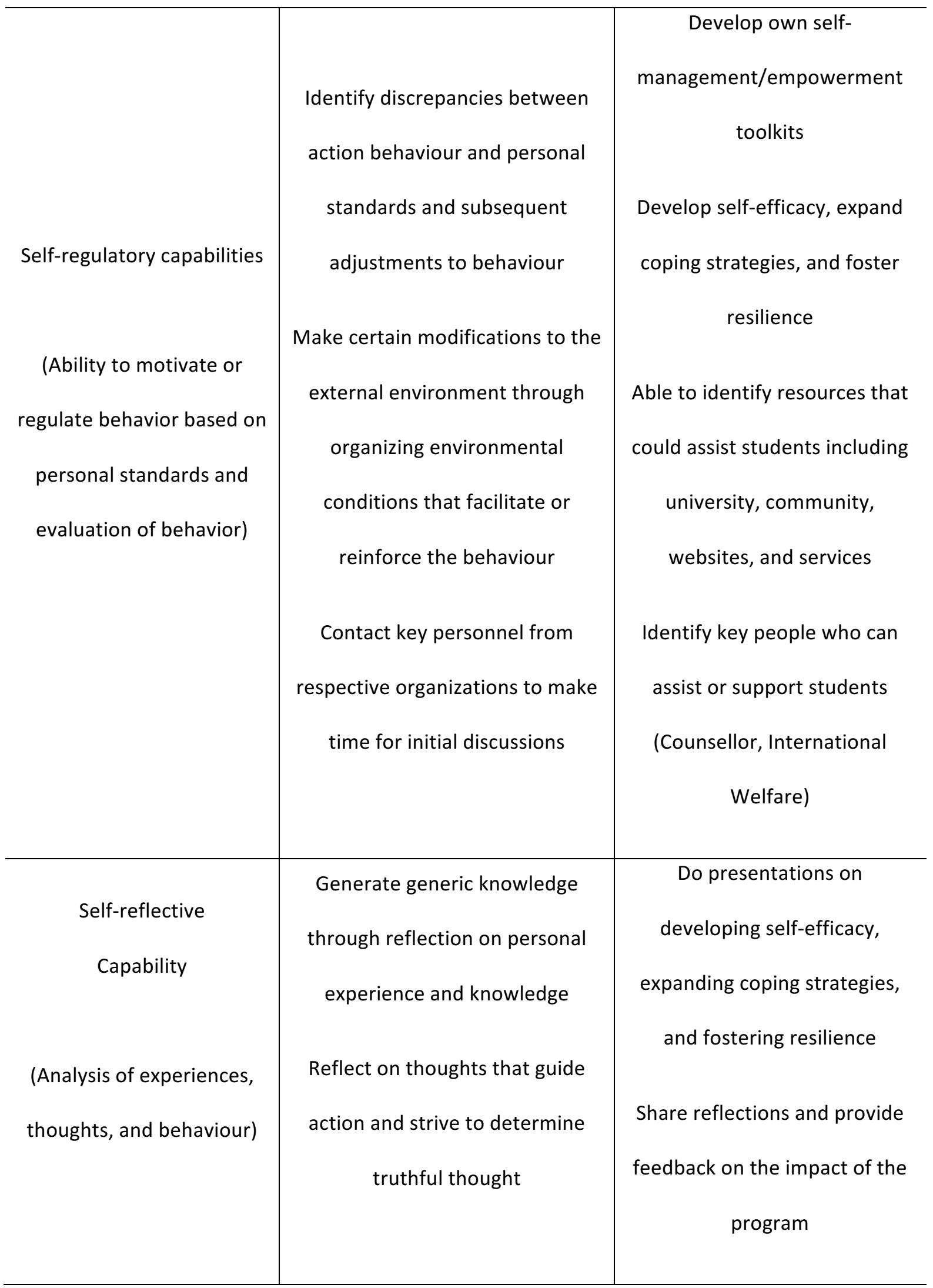




\begin{tabular}{c|c|c}
\hline $\begin{array}{c}\text { Assess self-efficacy, coping and } \\
\text { prosilience and impact of the }\end{array}$ & Be involved in the next \\
Work to be change & program as mentor \\
champions/purveyors & Evaluate the impact of the \\
program on personal and & \\
professional growth & \\
\hline
\end{tabular}

(Adapted from Mitchie, et al. 2014) 